\title{
Sociocultural and host factors related to extra-pulmonary tuberculosis in rural Bangladesh: A case control study
}

\author{
Karim MR ${ }^{1}$, Alam $\mathrm{MA}^{2}$, Mamun $\mathrm{SAA}^{3}$, Rahman $\mathrm{MA}^{4}$ \\ ${ }^{1}$ Epidemiology, OSD, Directorate General of Health Services, Mohakhali, Dhaka 1212. ${ }^{2}$ RCH National \\ Institute of Preventive and Social Medicine, Mohakhali, Dhaka-1212. ${ }^{3}$ Filaria Control Program CDC, \\ DGHS, Mohakhali. Dhaka-1212. ${ }^{4}$ Department of Epidemiology National Institute of Preventive and Social \\ Medicine. Mohakhali, Dhaka 1212. \\ Email: shameem.m25@gmail.com
}

\begin{abstract}
Bangladesh ranks sixth among higher TB burden countries. Extra-pulmonary TB contributes $12 \%$ of all tuberculosis cases in 2008. Risk factors for EPTB in Bangladesh are hypothesized to be different from pulmonary tuberculosis as seen in other high-burden countries. A case control study was conducted to compare the sociodemographic, household condition and lifestyle characteristics between extra pulmonary and pulmonary tuberculosis. This case control study was conducted in thirteen sub districts of Pabna, Shirajgonj and Cox's Bazar districts from January to June 2013. The samples were classified as either extra pulmonary tuberculosis EPTB (cases) or pulmonary tuberculosis PTB (controls). A total of 490 participants including 245 extra pulmonary tuberculosis (cases) and 245 pulmonary tuberculosis (controls), who were being enrolled in DOTS treatment for last six months, were interviewed for epidemiological and clinical information using a standardized questionnaire. Children, adolescent and younger adults had four-time higher risk of being manifested with extra pulmonary tuberculosis [Adjusted odds ratio (AOR) 3.97; 95\% Confidence Interval (CI) 1.10 to 14.35] and (AOR 4.50; 95\% CI 1.48 to 13.72). Respondents, who lived in their own houses showed three times more chance of getting extra pulmonary disease (AOR 3.11; 95\% CI 1.15 to 8.39). Extra pulmonary tuberculosis was seven to eight times more likely to occur among those whose resided in bedrooms ventilated with one $(p=.001)$ or more windows $(p=.004)$ and having window shutter made of glasses or wood slit raised the probability of getting extra pulmonary involvement by twenty times. Households using grain husk and leaves as cooking fuel revealed seven times higher chance of being manifested as extra pulmonary tuberculosis $(\mathrm{P}<.001)$. Extra pulmonary cases were three times more common among respondents, who had no history of exposure with known tuberculosis cases than those who had frequent exposure history (AOR 3.01; 95\% CI 1.24 to 7.34). Extra pulmonary tuberculosis was found 1.5 times more common among BCG vaccinated respondents than pulmonary tuberculosis (AOR 1.66; 95\% CI 1.06 to 2.58). Younger age, house ownership, bedroom ventilation, fuel material used for cooking, contact history and BCG vaccination status might be the important risk factors for the extra pulmonary manifestation of tuberculosis relative to pulmonary tuberculosis.
\end{abstract}

Key words: Host factors, Extra pulmonary tuberculosis, Bangladesh

\section{Introduction}

Tuberculosis (TB) remains one of the world's deadliest communicable diseases. In 2013, an estimated nine million people developed TB and 1.5 million died from the disease. ${ }^{1}$ The South East Asia Region (SEAR) accounts for 38\% (3.4 million new cases) of the global burden of TB in terms of incidence and Bangladesh contributes $18.5 \%$ of the total TB mortality in this region. ${ }^{2}$ Although the infection of $\mathrm{M}$. tuberculosis usually results in pulmonary $\mathrm{TB}$, other organs and tissues can also be affected, resulting in extra-pulmonary tuberculosis (EPTB). ${ }^{3-5}$ Total number of new TB 
cases has decreased in recent years, but the reduction in cases of extra-pulmonary tuberculosis (EPTB) has been smaller, resulting in a proportionate increase in EPTB compared to pulmonary tuberculosis (PTB). In Bangladesh, proportion of EPTB cases were $12 \%$ in 2008 and $18.5 \%$ in 2013 among all newly notified TB cases. ${ }^{6,7}$ EPTB receives less interest than pulmonary tuberculosis because of its low infectious potential. However, it is considered a serious clinical problem because of the diagnostic challenges encountered and the propensity to cause high morbidity and mortality. Lymph node tuberculosis comprised the highest number of EPTB in almost all studies. ${ }^{8-12}$ The central nervous system was found next most frequent site of EPTB involvement, followed in descending order by skeletal, pleural, abdominal, cutaneous, genitourinary, pericardial, disseminated (military), and breast tuberculosis. ${ }^{10}$ Literatures revealed, age, income, occupation, race, sex, malnutrition, vitamin D deficiency, biomass fuel exposure, HIV positivity, diabetes, renal disease, drinking unpasteurized milk, as important factors for extra-pulmonary tuberculosis. ${ }^{13-16}$ The other likely socio-cultural factors were female illiteracy, female economic dependency and their poor access to health care. ${ }^{4}$ Alcohol abuse, smoking habit, contact with PTB patients and BCG vaccination were observed less frequently among EPTB cases. ${ }^{17-21}$ Host related factors for EPTB varied according to geographic origin; female gender for Asian and north African, age for sub Saharan and HIV for European. ${ }^{14}$ Risk factor for EPTB cases in Bangladesh may be different to those in other countries but appropriate studies to investigate this are lacking. 3,20,22 A small number of hospital based clinical studies were conducted on EPTB in Bangladesh which described primarily the site of EPTB infection, diagnosis and treatment. This population based retrospective case control study was conducted to find out the differences in distribution of sociodemographic factors, household environment, contact with known TB cases and behavioral factors between Pulmonary TB and EPTB cases. The study findings will help policy makers formulating new health promotion intervention to combat EPTB, giving more emphasis on these factors.

\section{Materials and Methods}

Cases and controls: This case control study was conducted in thirteen sub districts of Pabna, Shirajgonj and Cox's Bazar districts from January to June 2013. The samples were classified as either extra-pulmonary tuberculosis EPTB (cases) or pulmonary tuberculosis PTB (controls). According to the World Health Organization (WHO) definition, EPTB is defined as a tuberculosis affecting organs other than the lungs, for example; pleura, lymph nodes, genitourinary tract, bones, meninges, and so on. EPTB cases that involved $>1$ EPTB disease sites were classified according to the major site. Cases of disseminated TB and cases with concurrent EPTB-PTB were excluded from our principal analysis, because they were not distinctly classifiable as either EPTB or PTB.

Sample size determination: Sample size was determined using Sample power IBM software, assuming anticipated probability of "exposure" given "controls" $12 \%$, anticipated odds ratio 2 , $5 \%$ level of significance, $80 \%$ power. Estimated sample size was 245 EPTB cases and 245 PTB controls. A total of 490 participants, who were diagnosed and undergoing treatment for last six months, were recruited from the treatment register of the DOTS centers of thirteen sub-districts.

Data collection: Addresses of the respondents were collected from the DOTS centers' treatment registers so that the investigators could trace them to their home to obtain epidemiological and clinical information using a standardized questionnaire and in case of children necessary information were primarily collected from the mother of the children. Epidemiological data included demographic information, life style variables, household conditions and contact characteristics of the study subjects. Original clinical records were reviewed as needed.

Ethical consideration: Prior conducting the study, ethical clearance was taken from the Bangladesh medical Research Council (BMRC) Ethical Review Committee.

Statistical analysis: The data was entered, cleaned and edited with the help of Software "Statistical Package for the Social Sciences" (SPSS) for 
windows version 20.0. To test the difference between the cases and the controls, we used the chi-square or Fisher exact tests, as appropriate, for categorical variables, and Student's t test, for continuous variables. To identify the risk factors for EPTB and to control for possible confounding factors, all variables associated with a level of significance of $\mathrm{P}<0.20$ in the univariate analysis were included in a stepwise multiple logistic regression analysis. On analyzing risk factors for EPTB, we used the patients with PTB as a reference. Interaction factors were analyzed, but not included in the final model, as they were not found to be significant. Adjusted Odds ratios (OR), 95\% confidence intervals $(95 \% \mathrm{CI})$ and $\mathrm{P}$ values (a $\mathrm{p}$ value of $<0.05$ as the criterion for statistical significance of associations) were calculated for each potential risk factor.

\section{Result}

This case control study was carried out within 245 extra-pulmonary tuberculosis cases and 245 pulmonary tuberculosis patients (controls) to compare the risk factors associated with two types of tuberculosis. Among the extra-pulmonary cases, lymph node $(\mathrm{n}=98,40 \%)$ contributed the highest proportion followed by pleura, spine, intestine, bone, meninges, skin, and others e.g. breast, epididymis, endometrium etc.

Pulmonary tuberculosis was mostly diagnosed at DOTS centers and Government hospitals but extra-pulmonary tuberculosis was detected in higher proportion at private health facilities. Pulmonary tuberculosis patients were mostly detected by sputum smear examination and chest radiographs while extra pulmonary tuberculosis patients were mainly diagnosed through biopsy, histopathology and immunological test. Some patients with pleural involvement and patients with bone or spine tuberculosis were also preliminarily detected by radiographic procedure.

Cough, hemoptysis and night sweats were commonly presented symptoms by pulmonary tuberculosis patients; on the contrary fever, anorexia, weight loss and weakness were almost equally reported by both cases and controls. Several other general and site specific symptoms were also mentioned by the "others" category participant.

The result is presented here under following subheading.

1. Sociodemographic characteristics of cases and controls

2. Household characteristics

3. Cooking environment and fuel type

4. Contact and behavioral characteristics

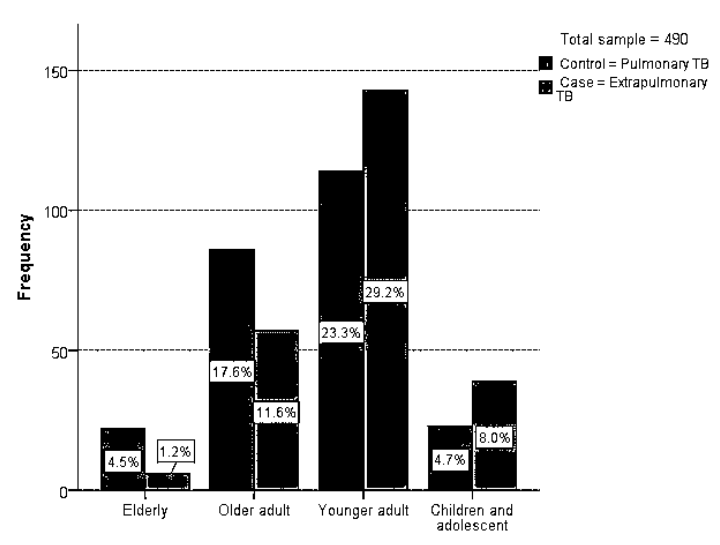

Sociodemographic characteristics [Table I]: Statistically significant difference was observed in mean age of the cases 31.01 (15.45) and control 37.63 (15.70), $(\mathrm{p}=0.002)$. Younger adults, children and adolescent were five to six times more likely to develop extra-pulmonary tuberculosis than elderly samples, $p=0.001$. The proportion of extra-pulmonary tuberculosis in female was significantly higher than that of male while the reverse is observed in male samples. $p=$ 0.013. Frequency of PTB was twice as much common in older males compared to the females in the study. (Fig. 1)

Extra-pulmonary tuberculosis was statistically significantly related with the mobility of the family members, $(\mathrm{p}=.01)$. Educational status and development of extra-pulmonary tuberculosis was also associated, as respondents who completed higher secondary education, had almost two times more chance of acquiring extra-pulmonary disease after being infected with Tuberculosis $\mathrm{p}=$ 0.001 . Occupation was significantly linked with extra-pulmonary tuberculosis. 
Table I: Comparison of cases (extra pulmonary tuberculosis EPTB) and controls (pulmonary tuberculosis PTB) according to Socio-demographic characteristics

\begin{tabular}{|c|c|c|c|c|}
\hline Characteristics & $\begin{array}{c}\text { Controls } \\
\text { (Pulmonary } \\
\text { TB) } \\
\mathrm{N}=245 \\
\mathrm{n}(\%)\end{array}$ & $\begin{array}{c}\text { Cases } \\
\text { (Extra } \\
\text { pulmonary TB) } \\
\mathrm{N}=245 \\
\mathrm{n}(\%) \\
\end{array}$ & $\begin{array}{l}\text { Crude odds } \\
\text { ratio } \\
(95 \% \mathrm{CI})\end{array}$ & $\mathrm{p}$ \\
\hline \multicolumn{5}{|l|}{ Age } \\
\hline$†$ Elderly & $22(79)$ & $6(21)$ & & \\
\hline Older adult & $86(60)$ & $57(40)$ & $\begin{array}{l}2.43(0.93 \\
6.36)\end{array}$ & .071 \\
\hline Younger adult & $114(44)$ & $143(56)$ & $\begin{array}{l}4.60(1.81, \\
11.72)\end{array}$ & $.001 *$ \\
\hline \multirow[t]{2}{*}{$\begin{array}{l}\text { Children and } \\
\text { adolescent }\end{array}$} & $23(37)$ & $39(63)$ & $\begin{array}{l}6.22(2.20 \\
17.58)\end{array}$ & $.001 *$ \\
\hline & Mean(SD) & Mean(SD) & & \\
\hline $\begin{array}{l}\text { Age in years } \\
\text { Sex }\end{array}$ & $37.63(15.70)$ & $31.01(15.45)$ & & $.002 * *$ \\
\hline † Male & $158(55)$ & $131(45)$ & & \\
\hline Female & $87(42)$ & $114(58)$ & $\begin{array}{l}1.58(1.10 \\
2.27)\end{array}$ & $.013 *$ \\
\hline \multicolumn{5}{|l|}{$\begin{array}{l}\text { Mobility of the family } \\
\text { members }\end{array}$} \\
\hline Changed regularly & $18(58)$ & $13(42)$ & $\begin{array}{c}0 . .89(0.42 \\
1.90)\end{array}$ & .76 \\
\hline Changed irregularly & $94(43)$ & $124(57)$ & $\begin{array}{l}1.63(1.12 \\
2.35)\end{array}$ & $.01^{*}$ \\
\hline \multicolumn{5}{|l|}{ Educational status } \\
\hline$\dagger$ Preprimary & $127(56)$ & $98(44)$ & & \\
\hline Primary to secondary & $80(49)$ & $83(51)$ & $\begin{array}{l}1.35(.90 \\
2.02)\end{array}$ & .15 \\
\hline $\begin{array}{l}\text { Higher secondary and } \\
\text { above }\end{array}$ & $38(37)$ & $68(63)$ & $\begin{array}{l}2.18(1.35 \\
3.53)\end{array}$ & $.001 *$ \\
\hline \multicolumn{5}{|l|}{ Occupational status } \\
\hline$\dagger$ Unemployed & $32(65)$ & $17(35)$ & & \\
\hline Homemaker & $59(48)$ & $63(52)$ & $\begin{array}{l}2.01(1.01 \\
3.99)\end{array}$ & $.05^{*}$ \\
\hline Students & $21(34)$ & $41(66)$ & $\begin{array}{l}3.68(1.67 \\
8.09)\end{array}$ & $.001 *$ \\
\hline Service and business & $54(47)$ & $60(53)$ & $\begin{array}{l}2.09(1.05 \\
4.19)\end{array}$ & $.04 *$ \\
\hline Laborer & $79(55)$ & $64(45)$ & $\begin{array}{l}1.53(0.78, \\
2.99)\end{array}$ & .22 \\
\hline \multicolumn{5}{|l|}{ Expenditure category } \\
\hline$\dagger$ Less than 5000 & $61(58)$ & $45(42)$ & & \\
\hline 5000 to 10000 & $118(53)$ & $105(47)$ & $\begin{array}{c}1.21(0.76 \\
1.92) \\
1.95(1.19 \\
3.21)\end{array}$ & $.008 *$ \\
\hline
\end{tabular}

$\dagger=$ reference category, $*=$ statistically significant in chi-square test, $* *=$ statistically significant in $\mathrm{t}$ test $\mathrm{CI}=$ confidence interval

Homemakers, service holders and students had two to three times increased odds of having extrapulmonary tuberculosis when compared to unemployed respondents. $\mathrm{p}=0.05, \mathrm{p}=0.01$. Higher income category respondents showed increased frequency of extra-pulmonary cases and deferred significantly from lower income group. $\mathrm{p}$ $=0.008$.
Table II: Comparison of cases (extra-pulmonary tuberculosis EPTB) and controls (pulmonary tuberculosis PTB) according to household characteristics.

\begin{tabular}{|c|c|c|c|c|}
\hline Characteristics & $\begin{array}{c}\text { Controls } \\
\text { (Pulmonary } \\
\text { TB) } \\
\mathrm{N}=245 \\
\mathrm{n}(\%) \\
\end{array}$ & $\begin{array}{c}\text { Cases } \\
\text { (Extra } \\
\text { pulmonary TB) } \\
\mathrm{N}=245 \\
\mathrm{n}(\%)\end{array}$ & $\begin{array}{l}\text { Crude odds } \\
\text { ratio } \\
(95 \% \mathrm{CI})\end{array}$ & $\mathrm{p}$ \\
\hline \multicolumn{5}{|l|}{ House ownership } \\
\hline$\dagger$ Own house & $219(48)$ & $234(52)$ & & \\
\hline Rental houses & $26(70)$ & $11(30)$ & $2.53(1.22,5.23)$ & $.01 *$ \\
\hline \multicolumn{5}{|l|}{$\begin{array}{c}\text { Physical condition of } \\
\text { household }\end{array}$} \\
\hline Middle class & $161(52)$ & $149(48)$ & $\begin{array}{c}0.90(0.61 \\
1.33)\end{array}$ & .60 \\
\hline Rich & $7(29)$ & $17(71)$ & $\begin{array}{c}2.37(0.93 \\
6.03)\end{array}$ & .07 \\
\hline$†$ No window & $56(65)$ & $30(35)$ & & \\
\hline Only one window & $68(51)$ & $66(49)$ & $\begin{array}{c}1.81(1.04 \\
3.17)\end{array}$ & $.037^{*}$ \\
\hline Two or more window & $121(45)$ & $149(55)$ & $\begin{array}{c}2.30(1.39 \\
3.81)\end{array}$ & $.001^{*}$ \\
\hline \multicolumn{5}{|l|}{$\begin{array}{c}\text { Windows opening } \\
\text { status }\end{array}$} \\
\hline$\dagger$ No window & $56(65)$ & $30(35)$ & & \\
\hline Open irregularly & $8(42)$ & $11(58)$ & $\begin{array}{c}2.57(0.93 \\
7.07)\end{array}$ & .068 \\
\hline Open regularly & 181(47) & 204(53) & $\begin{array}{c}2.10(1.29 \\
3.42)\end{array}$ & $.003^{*}$ \\
\hline \multicolumn{5}{|l|}{ Window material } \\
\hline$\dagger$ Fixed or sealed or tin & $64(67)$ & $32(33)$ & & \\
\hline Permanent opening & $16(39)$ & $25(61)$ & $\begin{array}{l}3.13(1.47 \\
\quad 6.67)\end{array}$ & $.003^{*}$ \\
\hline Glass, wood slit & $165(47)$ & $188(53)$ & $\begin{array}{l}2.28(1.42 \\
3.66)\end{array}$ & $.001^{*}$ \\
\hline \multicolumn{5}{|l|}{ Type of latrine } \\
\hline$\dagger$ Pit & $39(61)$ & $25(39)$ & & \\
\hline Ring slab & $140(47)$ & $159(53)$ & $\begin{array}{c}1.77(1.02 \\
3.07)\end{array}$ & $.04 *$ \\
\hline Septic tank & $66(52)$ & $61(48)$ & $\begin{array}{c}1.44(0.78 \\
2.66)\end{array}$ & .24 \\
\hline \multicolumn{5}{|l|}{ Electricity supply } \\
\hline$\dagger$ Absent & $97(59)$ & $67(41)$ & & \\
\hline Available & $148(45)$ & $178(55)$ & $1.74(1.19,2.55)$ & $.004^{*}$ \\
\hline \multicolumn{5}{|l|}{ Kitchen ventilation } \\
\hline †ventilated & $160(54)$ & 139(46) & & \\
\hline Not ventilated & $85(44)$ & $106(56)$ & $1.44(1.00,2.07)$ & $.05^{*}$ \\
\hline $\begin{array}{c}\text { Stove type } \\
\dagger \text { Partially covered } \\
\text { stove }\end{array}$ & $56(59)$ & $39(41)$ & & \\
\hline $\begin{array}{l}\text { Open fire } \\
\text { Fuel type }\end{array}$ & $189(48)$ & $206(52)$ & $1.57(.99,2.46)$ & $.05^{*}$ \\
\hline$\dagger$ Wood and dung & $233(52)$ & $212(48)$ & & \\
\hline Grain husk & $12(27)$ & $33(73)$ & $3.02(1.5,6.00)$ & $.001^{*}$ \\
\hline \multicolumn{5}{|l|}{ Biofuel exposure } \\
\hline$\dagger$ Not exposed & $149(55)$ & $121(45)$ & & \\
\hline exposed & $95(44)$ & $123(56)$ & $1.59(1.11,2.28)$ & $.01 *$ \\
\hline
\end{tabular}

Household characteristics [Table II]: Respondents lived in their own houses, had more than two times higher odds of getting extra- 
pulmonary tuberculosis than those, who did not have their own living space $\mathrm{p}=0.01$.

Table III: Contact and behavioral characteristics of Cases with extra-pulmonary tuberculosis (EPTB) compared to controls with pulmonary tuberculosis (PTB).

\begin{tabular}{|c|c|c|c|c|}
\hline Characteristics & $\begin{array}{l}\text { Controls } \\
\text { (Pulmonary } \\
\text { TB) } \\
\mathrm{N}=245 \\
\mathrm{n}(\%)\end{array}$ & $\begin{array}{c}\text { Cases } \\
\text { (Extra- } \\
\text { pulmonary } \\
\mathrm{TB}) \\
\mathrm{N}=245 \\
\mathrm{n}(\%) \\
\end{array}$ & $\begin{array}{l}\text { Crude odds } \\
\text { ratio } \\
(95 \% \mathrm{CI})\end{array}$ & $\mathrm{p}$ \\
\hline \multicolumn{5}{|l|}{ Contact relation } \\
\hline $\begin{array}{l}\dagger \text { Family } \\
\text { contact }\end{array}$ & $49(58)$ & $35(42)$ & & \\
\hline $\begin{array}{l}\text { Neighborhood } \\
\text { contact }\end{array}$ & $55(54)$ & $47(46)$ & $1.19(0.67,2.14)$ & \\
\hline No contact & $141(46)$ & $163(54)$ & $1.62(0.99,2.64)$ & \\
\hline \multicolumn{5}{|l|}{ Frequency of contact } \\
\hline $\begin{array}{l}\dagger \text { Frequent } \\
\text { contact }\end{array}$ & $60(63)$ & $36(37)$ & & \\
\hline $\begin{array}{l}\text { Infrequent } \\
\text { contact }\end{array}$ & $42(47)$ & $48(53)$ & $1.90(1.06,3.42)$ & $.03 *$ \\
\hline No contact & $143(47)$ & $161(53)$ & $1.88(1.17,3.00)$ & $.009 *$ \\
\hline \multicolumn{5}{|l|}{ Smoking } \\
\hline$\dagger$ Regular & $79(59)$ & $54(41)$ & & \\
\hline Irregular & $16(55)$ & $13(45)$ & $1.19(0.53,2.67)$ & \\
\hline Never & $150(46)$ & $178(54)$ & $1.74(1.15,2.61)$ & $.008^{*}$ \\
\hline \multicolumn{5}{|l|}{$\begin{array}{l}\text { Presence of Smokers in } \\
\text { the family }\end{array}$} \\
\hline $\begin{array}{l}\dagger \text { Smoker in } \\
\text { the family }\end{array}$ & $153(55)$ & $127(45)$ & & \\
\hline $\begin{array}{l}\text { No smoker in } \\
\text { the family }\end{array}$ & $92(44)$ & $118(56)$ & $1.55(1.08,2.22)$ & $.02 *$ \\
\hline \multicolumn{5}{|l|}{$\begin{array}{l}\text { Living in the same room } \\
\text { with smoker }\end{array}$} \\
\hline$\dagger$ Yes & $58(59)$ & $41(41)$ & & \\
\hline No & $187(48)$ & $204(52)$ & $1.54(0.99,2.41)$ & \\
\hline \multicolumn{5}{|l|}{ Sleeping in same bed } \\
\hline †yes & $22(63)$ & $13(37)$ & & \\
\hline no & 223(49) & $232(51)$ & $.57(.28,1.15)$ & \\
\hline \multicolumn{5}{|l|}{ BCG vaccination } \\
\hline$\dagger$ †es & $122(57)$ & $94(43)$ & & \\
\hline No & $123(45)$ & $151(55)$ & $1.59(1.11,2.28)$ & $.04 *$ \\
\hline \multicolumn{5}{|l|}{ Food security status } \\
\hline $\begin{array}{l}\dagger \text { Poor food } \\
\text { security }\end{array}$ & 137(59) & $96(41)$ & & \\
\hline $\begin{array}{l}\text { Average food } \\
\text { security }\end{array}$ & $70(42)$ & $96(58)$ & $1.96(1.31,2.93)$ & $.001^{*}$ \\
\hline $\begin{array}{l}\text { Good food } \\
\text { security }\end{array}$ & $38(42)$ & $53(58)$ & $1.99(1.22,3.25)$ & $.006^{*}$ \\
\hline
\end{tabular}

Higher proportion of EPTB was observed in respondents who belonged to higher income category in this sample. Number of windows in main bed, materials used to construct window's shutter and windows daily opening status, revealed significant relationship with the development of extra-pulmonary tuberculosis. Presence of window and shutter material revealed significant association with the development of extra-pulmonary tuberculosis as samples lived in houses with fixed opening or vent in the wall had three times more possibilities of getting EPTB, $\mathrm{p}<0.001$ and whose bedroom window shutter made of glass or wood slit, probability of developing EPTB doubled. Respondents, residing in bedrooms with two or more windows had two times higher chance of developing extrapulmonary tuberculosis, $\mathrm{p}=0.001$. Extrapulmonary tuberculosis found to be two times more common among respondents who opened their bedroom windows regularly $\mathrm{p}=0.003$. Almost all tuberculosis patients, $\mathrm{n}=494(99 \%)$ took tube well water for drinking and cooking. Possessing electricity and ring slab latrine, showed significant variation in their distribution between cases and controls ( $\mathrm{p}=0.04, \mathrm{p}=0.004)$. Respondents who were exposed to inadequate kitchen ventilation, open fire cooking, cooking fuel smoke had 1.5 times more likely to have EPTB. Participants, who used grain husk and leaves primarily as cooking fuel were three times more likely to have extra-pulmonary tuberculosis $\mathrm{p}=0.001$.

Contact and behavioral characteristics [Table III]: Respondents who reported infrequent contact or who had no known contact with known TB cases were twice likely to have EPTB compared to the ones who reported frequent exposure with a known TB case. This finding was statistically significant $p=0.03, p=0.009$. Never smokers were almost two times more likely to present themselves with extra-pulmonary manifestations than their regular smoker counterpart. $\mathrm{p}=0.008$. When stratified analysis was done, the mean smoking duration was found significantly different between cases and controls. Respondents, who had no smokers in their family, had 1.5 times more probability of getting extrapulmonary tuberculosis, $\mathrm{p}=0.02$. Extrapulmonary tuberculosis was almost 1.6 times more common among samples who were not vaccinated with BCG $p=0.04$. Food security status had a significant relationship with EPTB as revealed by our analysis, which showed frequency of PTB was higher in respondents with poor food security whereas, EPTB was found to be in greater 
proportion among respondents with average and good food security $\mathrm{p}=0.001, \mathrm{p}=0.006$.

\section{Exploring best predictors for extra-pulmonary} tuberculosis [Table IV]: In univariate analysis, several socio demographic factors and household characteristics, cooking environment, contact history and behavioral characteristics were found related with the extra-pulmonary manifestation of tuberculosis. Hence, a binary logistic regression model was constructed to find out the important predictors of EPTB adjusting for other factors.

The predictors in the model revealed that younger age, house ownership, presence of window in main bedroom, window material, primarily used fuel category, frequency and duration of contact with a PTB case, BCG vaccination found to be associated with extra-pulmonary tuberculosis when adjusted for other factors.

Children, adolescent and younger adults had fourtime higher risk of being manifested with extrapulmonary tuberculosis [Adjusted odds ratio (AOR) 3.97; 95\% Confidence Interval (CI) 1.10 to 14.35,$](\mathrm{p}=.035)$ and (AOR $4.50 ; 95 \% \mathrm{CI} 1.48$ to 13.72$),(p=.008)$. Samples lived in their own houses showed three times more chance of getting EPTB. (AOR 3.11; 95\% CI 1.15 to 8.39 ) ( $\mathrm{p}=$ 0.025). Presence of one (AOR 8.20; 95\% CI 2.29 to 29.34) $(\mathrm{p}=.001)$ or more windows (AOR 7.00; $95 \%$ CI 1.85 to 26.42$)(\mathrm{p}=.004)$ in bed room increased seven to eight times higher chance to be presented as extra-pulmonary tuberculosis. Bedroom window shutter made with glasses or wood slit raised the probability of getting extrapulmonary case by twenty times $(\mathrm{p}<.001)$. Respondents, whose households used grain husk and leaves as primary cooking fuel revealed seven times more possibilities of having extrapulmonary tuberculosis (AOR 6.85; 95\% CI 2.70 to 17.42 ).

Extra-pulmonary tuberculosis was three times more common among respondents, who had no history of exposure with tuberculosis cases than those exposed frequently (AOR 3.01; 95\% CI 1.24 to 7.34). Study participants, who were not BCG vaccinated, were 1.5 times more prone to develop EPTB than PTB (AOR 1.66; 95\% CI 1.06 to 2.58).
Table IV: Predictors for extra pulmonary tuberculosis Binary logistic regression model to determine independent risk factors for extra-pulmonary tuberculosis EPTB relative to pulmonary tuberculosis PTB

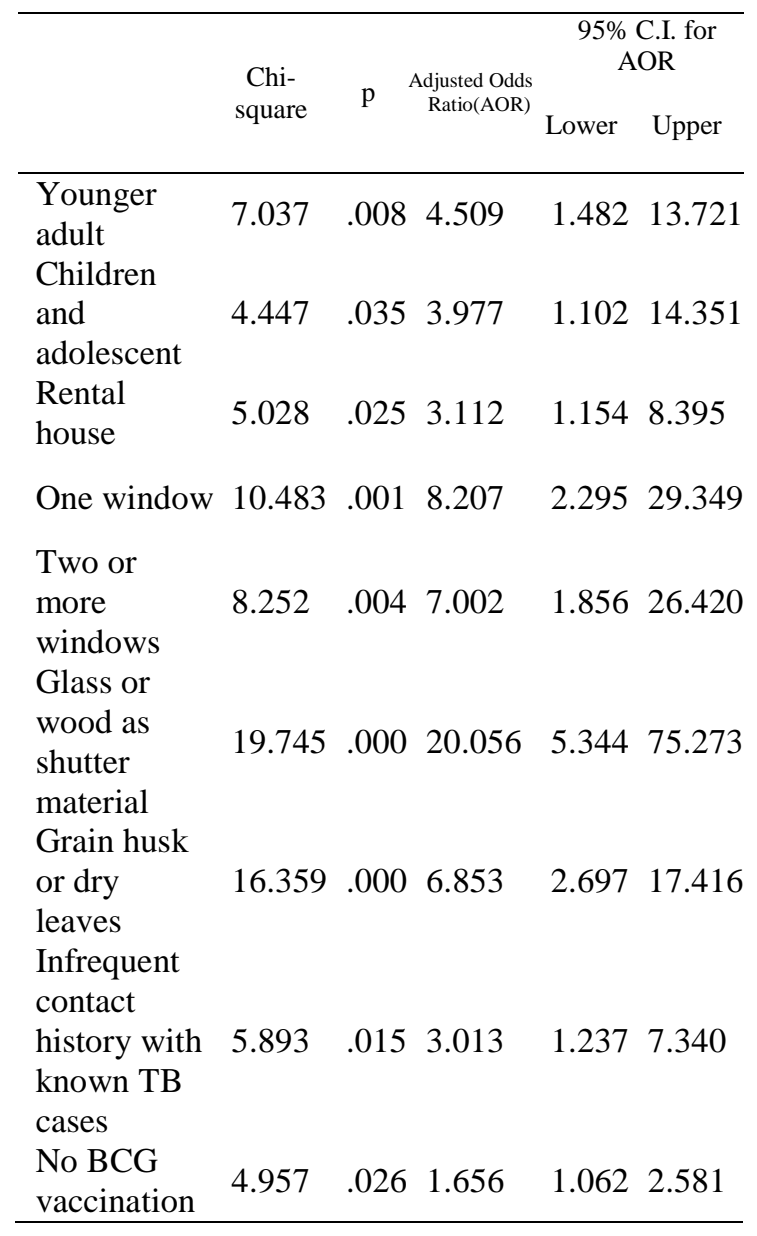

OR = Odds Ratio, $\mathrm{CI}=$ Confidence interval

\section{Discussion}

Extra-pulmonary tuberculosis was found in higher proportion within the younger age categories and the reverse was observed in case of pulmonary tuberculosis. It was consistent with the research findings of Karim et al, ${ }^{20}$ Chandrasekhar et al. and Gonzalez et al, who reported younger age is a risk factor for EPTB but contradicts with the study of Garcia-Rodriguez et al, where proportion of EPTB was found higher among older age catergories. ${ }^{3,17,21}$ Current Study showed females suffered more from EPTB than PTB, which was similar with the finding of Quddus et al. ${ }^{22}$ and Zhenhua et al. ${ }^{17}$ Literature supported that women 
may have a higher rate of progression to disease in their reproductive years, which is thought to be contributed by hormonal factors, whereas men have higher rates at older ages. $3,13,14,17$

After being infected primarily with TB bacillus, the probability of reactivation at an extrapulmonary site may be higher at younger ages and reactivation of $\mathrm{TB}$ is common in lungs at older ages. This may be due to decreased local immunity in the lungs in the elderly as a result of associated malnutrition, vitamin D deficiency, life-style factors (smoking) or diseases such as emphysema and bronchitis. ${ }^{10,13,23}$ Adequate ventilation of the bedroom and material used as shutter for window (type of window material), were found statistically associated with EPTB, because of the fact that window-shutter made of glass or wood slit permits more air and light in the living space and makes indoor environment less humid, dry and healthier. EPTB found more common in households, who used grain husk and dry leaves as cooking fuel because on combustion, these cooking materials produce "less volatile substance" and "particulate matter of 2.5" compared to wood or dry dung. An increase in emission of smoke, might distort the innate immunity of the host by disrupting macrophage function of the lung tissue and facilitate to develop pulmonary tuberculosis. ${ }^{24-26}$ Respondents, who had experienced frequent exposure to a known PTB case, were more likely to develop pulmonary manifestations, on the contrary, patients with infrequent exposure history had more chance to be manifested with EPTB. BCG vaccination plays an important role in preventing milliary tuberculosis and tubercular meningitis. This study showed that respondents, who were not vaccinated with $B C G$, had more chance to develop EPTB. In the current study, according to the site of primary involvement among the EPTB cases, lymph node $(\mathrm{n}=98,40 \%)$ contributed the highest proportion followed by pleura, spine, intestine, bone, meninges, skin, and others e.g. breast, epididymis, endometrium, testis etc. which is consistent with the finding of the study conducted by Karim et al. ${ }^{20}$ A hospital based study conducted in Shaheed Ziarur Rahman Medical College showed that 50\% of all EPTB cases admitted had lymph node manifestations followed by tubercular pleural effusion (15\%). ${ }^{22}$ This finding is also comparable to earlier studies from Nepal, Afghanistan, Saudi
Arabia and Turkey. ${ }^{3,23,27}$ The study included an approximately complete sampling of all active cases of EPTB and pulmonary TB from the study population over six months study period. Thus, the researcher attempted to reduce the chance of selection bias and recall bias that might confound the association between variables of interest and EPTB. Other factors, such as the virulence of the M. tuberculosis strains, mode of transmission of mycobacterium and the innate immunity of the host may contribute to differences in the risk of acquiring EPTB, which were beyond the scope of the study. Assessment of previous BCG vaccination might provide erroneous interpretation of the vaccination state, which appear in (7-11) \% of the population reporting scar in their arm. ${ }^{27}$

Conclusion: Results of our study suggest that younger age, house ownership, bedroom ventilation, fuel used for cooking, frequency of contact and BCG vaccination may be independent risk factors for the development of EPTB, relative to PTB. To attain an ample understanding of the pathogenesis of EPTB, the role of microbial factors must be identified in future studies.

\section{Acknowledgement}

We acknowledge Directorate General of Health Services and Bangladesh Medical Research Council for their institutional and administrative support.

\section{References}

1. World Health Organization. Global tuberculosis report 2014. Geneva 27, Switzerland: 2014. http://apps.who.int/iris/bitstream/10665/137094/1/97 89241564809_eng.pdf

2. World Health Organization. Tuberculosis control in the South-East Asia Region: annual report 2015. Regional Office for South- East Asia, New Delhi 110 002, India: 2015.

http://www.searo.who.int/tb/annual-tb-report-2015.

3. Sreeramareddy CT, Panduru KV, Verma SC, Joshi HS, Bates MN. Comparison of pulmonary and extra pulmonary tuberculosis in Nepal-a hospital-based retrospective study. BMC infectious diseases. 2008;8(1):8. 
4. Yang Z, Kong Y, Wilson F, Foxman B, Fowler AH, Marrs CF, et al. Identification of risk factors for extra pulmonary tuberculosis. Clinical infectious diseases. 2004;38(2):199-205.

5. Herchline TE. Tuberculosis [updated Dec 14, 2014]. http://emedicine.medscape.com/article/230802overview.

6. National Guidelines and Operation Manual for Tuberculosis Control, 4th Edition. National Tuberculosis Control Programme, DGHS, Ministry of Health and Family Welfare, Dhaka, Bangladesh: 2009.

7. World Health Organization. SEARO: Tuberculosis Control in the South East Asia Region. WHO report 2009. Regional Office for South- East Asia, New Delhi 110 002, India: 2009.

8. Gunal S, Yang Z, Agarwal M, Koroglu M, Arıcı ZK, Durmaz R. Demographic and microbial characteristics of extrapulmonary tuberculosis cases diagnosed in Malatya, Turkey, 2001-2007. BMC public health. 2011;11(1):154

9. Othman GQ, Ibrahim MIM, Rajaa YA. Comparison of clinical and sociodemographical factors in pulmonary and extrapulmonary tuberculosis patient in Yemen. Journal of Clinical and Diagnostic Research. 2011;5(2):191-95.

10. Fader T, Parks J, Khan NU, Manning R, Stokes S, Nasir NA. Extrapulmonary tuberculosis in Kabul, Afghanistan: a hospital-based retrospective review. International Journal of Infectious Diseases. 2010;14(2): e102-e10.

11. Kim MJ, Kim H-R, Hwang SS, Kim YW, Han SK, Shim Y-S, et al. Prevalence and its predictors of extrapulmonary involvement in patients with pulmonary tuberculosis. Journal of Korean medical science. 2009;24(2):237-41.

12. Hussain MW, Haque MA, Banu SA, Ekram AS, Rahman MF. Extrapulmonary tuberculosis: experience in Rajshahi chest disease clinic and chest disease hospital. TAJ: Journal of Teachers Association. 2004;17(1):16-19.

13. Al-Otaibi F, El Hazmi MM. Extra-pulmonary tuberculosis in Saudi Arabia. Indian Journal of Pathology and Microbiology. 2010;53(2):227.

14. Cailhol J, Decludt B, Che D. Sociodemographic factors that contribute to the development of extrapulmonary tuberculosis were identified. Journal of clinical epidemiology. 2005;58(10):1066-71.

15. Chandir S, Hussain H, Salahuddin N, Amir M, Ali F, Lotia I, et al. Extrapulmonary tuberculosis: a retrospective review of 194 cases at a tertiary care hospital in Karachi, Pakistan. JPMA The Journal of the Pakistan Medical Association. 2010;60(2):105.
Ullah S, Shah SH, Aziz-ur-Rehman KA, Begum N, Khan G. Extrapulmonary tuberculosis in Lady Reading Hospital Peshawar, NWFP, Pakistan: survey of biopsy results. Journal of Ayub Medical College Abbottabad. 2008;20(2):43-46.

16. García-Rodríguez JF, Álvarez-Díaz H, LorenzoGarcía MV, Mariño-Callejo A, Fernández-Rial Á, Sesma-Sánchez P. Extrapulmonary tuberculosis: epidemiology and risk factors. Enfermedades Infecciosas y Microbiología Clínica. 2011;29(7):50209.

17. Arcavi L, Benowitz NL. Cigarette smoking and infection. Archives of internal medicine. 2004;164(20):2206-16.

18. Leung CC, Li T, Lam TH, Yew WW, Law WS, Tam $\mathrm{CM}$, et al. Smoking and tuberculosis among the elderly in Hong Kong. American journal of respiratory and critical care medicine. 2004;170(9):1027-33

19. 19. Karim M, Choudhury S, Husain M, Faiz M. A clinical study on extrapulmonary tuberculosis. Journal of Bangladesh College of Physicians and Surgeons. 2006;24(1):19-28.

20. Gonzalez O, Adams G, Teeter L, Bui T, Musser J, Graviss E. Extra-pulmonary manifestations in a large metropolitan area with a low incidence of tuberculosis. The International Journal of Tuberculosis and Lung Disease. 2003;7(12):1178-85.

21. Quddus M, Uddin M, Bhuiyan M. Evaluation of extra pulmonary tuberculosis in Bangladeshi patients. Mymensingh medical journal: MMJ. 2014;23(4):758-63.

22. Davies P, Brown R, Woodhead J. Serum concentrations of vitamin D metabolites in untreated tuberculosis. Thorax. 1985;40(3):187-90.

23. Hudelson P. Gender differentials in tuberculosis: the role of socio-economic and cultural factors. Tubercle and lung disease. 1996;77(5):391-400.

24. Bukharie HA, Al-Rubaish AM, Mulhim AF, Qutub HO. Characteristics of pulmonary tuberculosis and extrapulmonary tuberculosis in immunocompetent adults. Tropical Medicine and Health. 2009;37(1):711 .

25. Lin H-H, Murray M, Cohen T, Colijn C, Ezzati M. Effects of smoking and solid-fuel use on COPD, lung cancer, and tuberculosis in China: a time-based, multiple risk factor, modelling study. The Lancet. 2008;372(9648):1473-83.

26. Ilgazli A, Boyaci $\mathrm{H}$, Basyigit İ, Yildiz $\mathrm{F}$. Extrapulmonary tuberculosis: clinical and epidemiologic spectrum of 636 cases. Archives of medical research. 2004;35(5):435-41. 